\title{
COMPARAÇÃO QUALITATIVA DE VIABILIDADE TÉCNICA DA UTILIZAÇÃO DE PAINEL DE MADEIRA PLÁSTICA VERSUS ALVENARIA CONVENCIONÁL NA CONSTRUÇÃO CIVIL
}

\author{
CESCON, GLÁUCIA \\ Universitária \\ Universidade do Estado de Minas Gerais (UEMG) \\ Minas Gerais; Brasil \\ glaucia_cescon@hotmail.com
}

\section{GOMES, MARCOS ANTÔNIO}

Vice diretor da UEMG unidade de João Monlevade Universidade do Estado de Minas Gerais

Minas Gerais; Brasil

marcos.antonio@uemg.br

\author{
DE ABREU, IGOR FERNANDES \\ Professor \\ Universidade do Estado de Minas Gerais \\ Minas Gerais; Brasil \\ igor.abreu@uemg.br
}

\author{
DE CASTRO, VINÍCIUS RESENDE \\ Professor \\ Universidade Federal de Viçosa \\ Minas Gerais; Brasil \\ vresende@gmail.com
}

\author{
DE PAULA, MARCOS OLIVEIRA \\ Professor \\ Universidade Federal de Viçosa \\ Minas Gerais; Brasil \\ modep@bol.com.br
}

\section{RESUMO}

As construções sempre desempenharam um papel fundamental no desenvolvimento da humanidade e passa, constantemente, por mudanças estruturais para melhor adaptação do homem. De maneira semelhante, os materiais para a realização das mesmas encontram-se em constante alterações. Dentre ele, o mais comumente utilizado vem sendo a alvenaria convencional, como na região de João Monlevade/MG, em que o bloco cerâmico é visto em novas construções a todo instante. Em contrapartida, a madeira é um material subutilizado, principalmente, por sua má utilização. Com isso, o trabalho buscou informações, referentes à durabilidade, conforto, manutenção, qualidade e segurança para entender qual o motivo de tal subutilização da madeira no processo construtivo, principalmente no processo de vedação interna. Baseado no trabalho de Gomes (2019), escolheu-se o painel de madeira plástica para analisar características técnicas entre ele e a alvenaria convencional, para assim, determinar qual dos dois materiais teria um melhor aproveitamento na construção civil da região, tendo em vista que próximo à mesma, possui um grande polo moveleiro, em Ubá, que pode ser um potencial construtor e fornecedor de tal material.

Palavras-chave: vedação, painéis, bloco cerâmico.

\begin{abstract}
Constructions have always played a fundamental role in the development of humanity and constantly undergo structural changes for the better adaptation of man. Similarly, the materials for making them are constantly changing. Among them, the most commonly used is conventional masonry, as in the João Monlevade region, where the ceramic block is seen in new constructions at all times. In contrast, wood is a material underused mainly by its misuse. Thus, the article aims to seek information regarding durability, comfort, maintenance, quality and safety to understand the reason for such underuse of wood in the construction process, especially in the process of internal sealing. Based on the work of Gomes (2019), the plastic wood panel was chosen to analyze technical characteristics between it and conventional masonry, in order to determine which of the two materials would have better use in the region's civil construction, considering that next to it, has a large furniture pole, in Ubá, which may be a potential builder and supplier of such material.
\end{abstract}

Keywords: fence, panels, ceramic block.

\section{INTRODUÇÃO}

Em seu livro Arquitetura Moderna, Scully Jr. (2002) aponta que as formas criadas por engenheiros não podem simplesmente ter surgido pelo desenvolvimento de novos materiais. Fato é que desde o começo da organização da sociedade moderna, muitas construções foram realizadas, mesmo com a falta dos recursos tecnológicos atuais, o que 
nos faz tentar compreender como puderam ser realizadas. São exemplos, as pirâmides do Egito, as Muralhas da China e tantas outras, que utilizaram materiais simples e facilmente disponíveis, como é o caso da madeira.

Segundo Pfeil e Pfeil (2012), a madeira é o material de construção mais antigo, apresentando ótima relação resistência/peso, facilidade de fabricação de diversos produtos industrializados e ótimo isolamento térmico, se comparado a outros materiais de construção convencionais. Sua utilização na construção civil se dá em estruturas temporárias, definitivas, decoração e piso, tanto externamente quanto internamente (STANT, 2018).

A Revista Exame (2013) aponta que a construção civil é uma alta consumidora de madeira, entretanto este material se torna de uso sensível ao ponderarmos que está sujeito à degradação tanto biológica quanto ao fogo (PFEIL \& PFEIL, 2012). Com isso, entender indicadores técnicos atrelados à qualidade de uso da madeira, torna-se um item fundamental para entender o comportamento de cada tipo desse material e agregar segurança ao uso.

Em contrapartida, ao analisarmos o cenário atual, na região de João Monlevade, grande é a utilização de alvenaria convencional para a execução de obras. Segundo Souza (2012), a preponderância de material construtivo nas construções civis brasileiras, ainda são as alvenarias, e Silva apud Simões (2017), afirma que o sistema construtivo do Brasil ainda é muito tradicional e artesanal. Para Cassar (2018), tal fato se dá pela facilidade de obtenção do produto, além de ser um bom isolante térmico e acústico, e resistente.

Assim sendo, fica nítido que, no Brasil, a alvenaria convencional é o principal dos produtos empregados na construção civil, enquanto que em países desenvolvidos como os Estados Unidos, os painéis têm participação mais significativa (REVISTA DA MADEIRA, 2003), uma vez que, à exemplo da madeira plástica, tal material existe no país há cerca de 20 anos, havendo uma boa inserção no mercado madeireiro (GOMES, 2019).

Não se sabe ao certo os motivos desse comportamento, podendo ser o pouco acesso às informações pela população ou poucos estudos voltados para essa área de forma a difundir os benefícios dos painéis. Levanta-se assim também a dúvida do impacto no setor civil.

Com isso, a proposta de estudo foi apresentada com o objetivo de estudar, de forma comparativa, a utilização de painéis de madeira plástica e da alvenaria de blocos cerâmicos de vedação, sob a perspectiva técnica determinando o melhor material para uso na construção civil.

A pesquisa propôs, como objetivo geral, realizar um avanço dos estudos de Gomes (2019), ao gerar uma comparação da utilização de painéis de madeira plástica e da alvenaria convencional de blocos cerâmicos de vedação, sob a perspectiva técnica, e levantar 5 indicadores das características dos produtos analisados, determinando tecnicamente o melhor material para uso na construção civil.

Dentre os objetivos específicos, apresenta-se: determinar os indicadores técnicos, como qualidade, durabilidade, conforto, segurança e manutenção, envolvidos na instalação e uso, tanto de painéis de madeira plástica quanto de alvenaria convencional, em estruturas na construção civil; realizar um estudo comparativo das variáveis coletadas, e, por fim, a avaliar o melhor material para aplicação civil.

Para isso, a pesquisa embasada em Gomes (2019), levantou dados relacionados à qualidade, durabilidade, conforto, segurança e manutenção para se entender o comportamento de cada um desses materiais no seu uso na construção civil. Parcerias como com a Universidade Federal de Viçosa (UFV), que possui um laboratório de estudos de painéis e energia da madeira, foram necessárias para a obtenção desses dados.

\section{METODOLOGIA}

A metodologia de pesquisa definida para este trabalho, segundo Gil (2017), é de objetivo exploratório, e procedimento técnico de revisão bibliográfica. Para Prodanov e Freitas (2013), ela possui uma natureza aplicada, com enfoque qualitativo. Exploratório, por se tratar de uma pesquisa. Revisão bibliográfica, por ser desenvolvida através de materiais já elaborados. Aplicada, por gerar conhecimentos a fim de possibilitar a criação de uma referência que demonstre aspectos técnicos atrelados ao uso de painéis de madeira-plástica comparado ao de alvenaria de vedação com blocos cerâmicos na construção civil. Qualitativa, por ocorrer a interpretação dos fenômenos sem técnicas estatísticas para posterior conclusão. 
O projeto foi concebido levando em consideração o método de engenharia (adaptado) apresentado por Montgomery e Runger (2009), em que se define o problema (levantamento das características técnicas de 2 produtos), identifica-se os fatores importantes que afetam o problema (itens técnicos primordiais, atrelados à ação humana e aspectos naturais), verifica-se os atributos (estudo aprofundado), conduz o experimento (por meio de comparação), refina-se o que se obtém (se necessário) e após, tira-se conclusões.

Assim sendo, a execução da proposta se dará em fases, 4 especificamente, sendo:

a) FASE A: precursora

A fase precursora objetivou a revisão bibliográfica aprofundada e alinhamento dos conhecimentos da aluna a executar a pesquisa; selecionou o tipo de painel a ser utilizado; estabeleceu uma parceria com o Laboratório de Painéis e Energia da Madeira (LAPEM) da Universidade Federal de Viçosa (UFV), onde teve acesso à teses e dados que embasaram o estudo;

b) FASE B: levantamento de indicadores

Teve por objetivo o levantamento de indicadores, que permitiram a obtenção de dados relativos à qualidade, durabilidade, conforto, segurança e manutenção envolvidos no uso tanto do painel de madeira-plástica, quanto da alvenaria de vedação com blocos cerâmicos.

Para a obtenção de dados, foram realizadas pesquisas online, em livros e teses, seguindo o método desenvolvido pelo LAPEM, uma vez que a tese base desenvolveu-se no local, havendo representatividade de dados para a tomada de decisões;

c) FASE C: comparativa

Obtidos os dados da fase anterior, os mesmos foram comparados em quesitos com interferência humana e de fabricação, uma vez que, definido alvenaria como empilhamento do material, tal processo é realizado de forma manual, gerando erros em seu desenvolvimento, e, segundo a fabricação, o mesmo é totalmente dependente de sua matéria prima, assim como a madeira-plástica.

\section{RESULTADOS E DISCUSSÃO}

Foram determinados os seguintes indicadores técnicos, para os dois produtos objeto de estudo:

a) QUALIDADE: por uma das definições do dicionário Michaelis (s/d), qualidade é o "grau de perfeição, de precisão ou de conformidade a certo padrão". Já Meira e Araújo (2016, p.14), conceituam o termo como um "conjunto de características do produto ou serviço em uso, as quais satisfazem as expectativas dos clientes", e afirmam que várias são as interpretações dadas à palavra, que variam de acordo com a conveniência e o processo em que se está sendo observado o produto ou serviço. Assim, para os produtos analisados, foram observados o peso, que influencia na carga exigida da fundação, a velocidade de montagem, para eficiência da construção, e o processo de fabricação, para observar a maior conformidade do produto, que possua menor capacidade de falhas e seja ecologicamente correto.

b) DURABILIDADE: está atrelado com a resistência e até à solidez do produto analisado (MICHAELIS, s/d), além de estar "relacionada às propriedades do material e à sua exposição ao longo do tempo, em um dado ambiente" (AECWEB, s/d).

c) CONFORTO: o termo conforto, entende-se por "bem-estar; comodidade material; aconchego" (MICHAELIS, s/d), e para Mussi (1996) define-se como a ausência de efeitos indesejáveis. Com isso, analisou-se o conforto termo acústico que os produtos proporcionam, além de características para uma construção e limpeza realizadas de formas satisfatórias, pensando na comodidade para os construtores e usuários.

d) SEGURANÇA: define-se como a "condição ou estado do que está livre de danos ou riscos." (MICHAELIS, s/d). Para Booth (apud SANTOS, 2015, p.3) "representa a ideia de "estar ou sentir-se seguro perante ameaças ou perigos"”. Assim, foram analisadas as questões de segurança em relação à transporte, montagem dos produtos e o comportamento deles durante o uso.

e) MANUTENÇÃO: refere-se à realização de atividades que mantenham as funções do produto com desempenho satisfatório (XENOS, 1998, apud KREMER e KOVALESKI, 2008), além de estar relacionada ao "ato de conservar 
ou de fazer durar algo em bom estado; preservação" (MICHAELIS, s/d). Portanto, observou-se ambos os materiais em relação à comportamento em reformas e limpeza.

No Quadro 1, observa-se o que foi possível levantar à respeito desses indicadores.

Quadro 1 - Determinação dos indicadores técnicos

\begin{tabular}{|c|c|c|}
\hline $\begin{array}{c}\text { Indicadores Produtos } \\
\text { técnicos }\end{array}$ & Painel de Madeira Plástica & $\begin{array}{c}\text { Alvenaria Convencional de Blocos } \\
\text { Cerâmicos de Vedação }\end{array}$ \\
\hline Qualidade & $\begin{array}{c}\text { Baixo peso, fácil e rápida } \\
\text { montagem em campo e baixo } \\
\text { consumo de energia e baixa } \\
\text { poluição. }\end{array}$ & $\begin{array}{c}\text { Alto peso, produto influenciado } \\
\text { pela origem da argila e processo de } \\
\text { produção do bloco, montagem } \\
\text { lenta. }\end{array}$ \\
\hline Durabilidade & $\begin{array}{c}\text { Persiste à umidade, rachaduras, } \\
\text { mofo, cupim, corrosão, podendo } \\
\text { ter contato com solo, sol, chuva e } \\
\text { poeira. }\end{array}$ & $\begin{array}{c}\text { Persiste à umidade, aos } \\
\text { movimentos térmicos, à pressão do } \\
\text { vento e infiltrações de águas } \\
\text { pluviais. }\end{array}$ \\
\hline Conforto & $\begin{array}{c}\text { Isolamento termo acústico, não } \\
\text { exige envernizamento, aceita } \\
\text { revestimento, aparenta madeira } \\
\text { sem nós, grande variação } \\
\text { dimensional. }\end{array}$ & $\begin{array}{c}\text { Isolamento termo acústico, só } \\
\text { aceita revestimento acompanhado } \\
\text { de chapisco, dimensões nem } \\
\text { sempre uniformes e superfícies } \\
\text { irregulares. }\end{array}$ \\
\hline Segurança & $\begin{array}{c}\text { Grande agarre à pregos e } \\
\text { parafusos, não libera farpas. }\end{array}$ & $\begin{array}{c}\text { Descolamento de revestimento, } \\
\text { quebra no transporte e na } \\
\text { construção e geração de entulhos. }\end{array}$ \\
\hline Manutenção & $\begin{array}{c}\text { Limpeza com água e sabão e, ao } \\
\text { retirar o painel, pode reutilizá-lo. }\end{array}$ & $\begin{array}{c}\text { Controle de rachaduras, mofos, e, } \\
\text { quando necessário, retirada com } \\
\text { quebras e geração de entulhos. }\end{array}$ \\
\hline
\end{tabular}

Fonte: a autora (2019).

Podemos então, com a interpretação do Quadro 1, comparar os produtos e comprovar que, em relação à qualidade, o painel torna-se melhor, por conta de seus materiais, que influenciam no seu baixo peso, e no controle de qualidade devido à origem, além de ser mais rapidamente montável, uma vez que os blocos cerâmicos são postos um por um, e o painel pode já vir com a parede inteiriça.

Já na questão de durabilidade, a comparação fica no empate, uma vez que ambos possuem boas resistência à seres ou ações que os poderiam danificar. Observando que o painel de madeira plástica persiste à agentes que a madeira, se não tratada, sofre com os seus ataques, como é o caso da persistência à rachaduras, mofo e cupim.

Para o conforto, ambos possuem isolamento térmico acústico, porém, a adição de revestimento no painel não se faz necessária, mas à gosto do cliente, pode ser aplicada diretamente nela, já o bloco cerâmico faz-se necessário a aplicação de um novo material, o chapisco, para a aplicação de revestimento. Além de que o painel possui uma variação dimensional ampla, ou seja, vários são os tamanhos que se pode obter dele, já os blocos, não possuem tamanha variedade, e podem vir com dimensões não uniformes e também com superfícies irregulares.

Observando a segurança, enquanto o painel possui um grande agarre de pregos e parafusos e não solta farpas, o que reduz o potencial de acidentes, o bloco cerâmico pode ter o seu revestimento descolado e quebras no transporte e na construção, gerando pilhas de entulho na obra, podendo gerar acidentes.

Já no âmbito de manutenção, além do painel de madeira plástica poder receber água e sabão em sua limpeza, o que a facilita bastante, em casos de reforma, por ela ser montável, acaba por ter uma facilidade em remover e adicionar paredes, já o bloco cerâmico não possui tal facilidade, muito pelo contrário, para sua remoção, há a quebra do material e geração de entulhos, porém, quando não há a necessidade de remoção, uma repintura pode ser o suficiente.

Observa-se também, que ambos os materiais necessitam de cuidados específicos, e, com isso, há a necessidade de mão de obra qualificada e especializada, uma vez que o conhecimento de técnicas para a aplicação e manutenção dos mesmos, pode prevenir futuras patologias, elevando a vida útil e agregando valor à construção. 


\section{CONCLUSÃO}

Após todas as análises e observações realizadas durante o estudo, pôde-se observar que a madeira sofreu, e ainda sofre, grande preconceito, principalmente quando o assunto se refere à sua existência permanente no interior da construção civil. Porém, o mesmo abriu portas para a fabricação de materiais como os painéis compostos de madeira, que podem ser usados como substitutos, quanto à vedação, da própria madeira, e até mesmo, de sistema antigos de vedação que perduram há muito tempo, como é o caso da alvenaria convencional de blocos cerâmicos. Além de que, o sistema utilizado na confecção de blocos cerâmicos de vedação encontra-se ultrapassado, uma vez que se trata de um processo antigo e quase sem atualização.

Após levantamento dos indicadores, análise e comparação entre painel de madeira plástica e alvenaria convencional de bloco cerâmico de vedação, pôde-se perceber que, o painel de madeira plástica se sobressai em relação à alvenaria convencional de bloco cerâmico de vedação, uma vez que possui melhor qualidade, conforto, segurança e manutenção, não havendo grandes divergências entre os produtos apenas no âmbito de durabilidade, ou seja, embora o sistema de blocos cerâmicos de vedação seja muito mais utilizado na atual conjuntura social, os painéis podem substituí-los de forma a não apenas manter o antigo funcionamento, mas elevando o padrão das construções. Porém, por ser um material novo no mercado, há uma falta de conhecimento sobre o mesmo, o que pode gerar certos receios em utilizá-la, havendo a necessidade de mão de obra qualificada e especializada, uma vez que os métodos de contrução usuais, como o bloco cerâmico de vedação não-portante, já são bem mais difundidos e conhecidos.

Como sugestão de trabalhos futuros, recomenda-se a análise financeira regional comparativa entre os produtos de estudo, o estudo de caso com aplicação em construções, e a realização de testes laboratoriais de resistência.

\section{AGRADECIMENTO}

Agradecemos à Universidade do Estado de Minas Gerais pela concessão de bolsa vigente pelo edital PIBIC/UEMG/PAPq concedido à autora e aos professores e aqui também autores do Laboratório de Propriedades da Madeira (LPM) da Universidade Federal de Viçosa (UFV) pela estimada orientação e ouvido, que foi capaz de permitir o avanço de algo aparentemente simples, mas que é apenas o começo.

\section{REFERÊNCIAS}

AECWEB. Durabilidade de estruturas de concreto está sujeita à ação do meio ambiente. [S. 1.]. Disponível em: https://www.aecweb.com.br/cont/m/rev/durabilidade-de-estruturas-de-concreto-esta-sujeita-a-acao-do-meioambiente_12727_10_0. Acesso em: 18 nov. 2019.

CASSAR, Bernardo Camargo. Análise comparativa de sistemas construtivos para empreendimentos habitacionais: alvenaria convencional $\mathbf{x}$ light steel frame. Orientador: Jorge dos Santos. 2018. 108 p. Projeto de Graduação (Engenheiro Civil) - Escola Politécnica, Rio de Janeiro, 2018. Disponível em: http://monografias.poli.ufrj.br/monografias/monopoli10025484.pdf. Acesso em: 31 out. 2019.

GIL, Antonio Carlos. Como elaborar projetos de pesquisa. 6. ed. Rio de Janeiro: Atlas, 2017.

GOMES, Roziani Maria. Uso de painéis fabricados com resíduos de madeira em construção habitacional. Orientador: Antônio Cleber Gonçalves Tibiriçá. 2019. 93 p. Dissertação (Mestrado em Arquitetura e Urbanismo) Universidade Federal de Viçosa, Minas Gerais, 2019.

KREMER, Cristian Dekkers; KOVALESKI, João Luiz. Determinação do momento ótimo para a realização da manutenção preventiva em equipamentos de uma indústria metalúrgica: um estudo voltado para a redução de custos. [S. 1.], 2008. Disponível em: http://www.4eetcg.uepg.br/oral/42_1.pdf. Acesso em: 18 nov. 2019.

MEIRA, Alexsandra Rocha; ARAÚJO, Nelma Mirian Chagas de. Qualidade na construção civil. João Pessoa: IFPB, 2016. 212 p. pdf.

MICHAELIS. Dicionário Brasileiro da Língua Portuguesa. $[\mathrm{S} . \quad 1],. \quad[\mathrm{s} / \mathrm{d}] . \quad$ Disponível em: http://michaelis.uol.com.br/moderno-portugues/. Acesso em: 18 nov. 2019. 
MONTGOMERY, Douglas C.; RUNGER, George C. Estatística aplicada e probabilidade para engenheiros. 4. ed. Rio de Janeiro: LTC, 2009.

MUSSI, Fernanda Carneiro. Conforto: revisão de literatura. USP, 1996. Disponível em: http://www.scielo.br/pdf/reeusp/v30n2/v30n2a06. Acesso em: 18 nov. 2019.

PFEIL, Walter; PFEIL, Michèle. Estruturas de Madeira. 6. ed. Rio de Janeiro: LTC, 2012.

PRODANOV, Cleber Cristiano; FREITAS, Ernani Cesar de. Metodologia do Trabalho Científico: Métodos e Técnicas da Pesquisa e do Trabalho Acadêmico. 2. ed. RS, 2013. Disponível em: https://drive.google.com/file/d/1lp5R-RyTrt6X8UPoq2jJ8gO3UEfM_JJd/view. Acesso em: 12 nov. 2019.

REMADE - REVISTA DA MADEIRA. Madeira na construção civil. [S. l.], Novembro 2003. Disponível em: http://www.remade.com.br/br/revistadamadeira_materia.php?num=456\&subject=E\%20mais\&title=Madeira\%20na $\% 20$ constru\%E7\%E3o\%20civil. Acesso em: 12 abr. 2019.

REVISTA EXAME. Construção civil é novo alvo na luta da madeira sustentável. [S. l.], 31 dez. 2013. Disponível em: https://exame.abril.com.br/negocios/dino/construcao-com-madeira-um-mercado-promissor-no-brasildino89094767131/. Acesso em: 12 mar. 2019.

SANTOS, Álvaro Moreira dos. Segurança e globalização: a perspetiva dos estudos críticos de Segurança. [S. 1.: s. n.], 2015.8 p. pdf.

SCULLY JR., V. Arquitetura Moderna. São Paulo: Cosac Naify, 2002.

SIMÕES, Dênis. Brasil tem muitos desafios no sistema construtivo: Método tradicional e artesanal de construção coloca o Brasil entre os últimos países em produtividade. Jornal do Comércio, [S. 1.], 12 set. 2017. Disponível em: https://www.jornaldocomercio.com/_conteudo/2017/08/especiais/construcao_civil_2017/581591-brasil-tem-muitosdesafios-no-sistema-construtivo.html. Acesso em: 31 out. 2019.

SOUZA, Laurilan Gonçalves. Análise comparativa do custo de uma casa unifamiliar nos sistemas construtivos de alvenaria, madeira de lei e Wood Frame. SC: [s. n.], 2012. 20 p. pdf.

STANT. O uso da madeira na construção civil: quais são as melhores aplicações?. [S. $l$.], 30 maio 2018. Disponível em: <http://www.stant.com.br/o-uso-da-madeira-na-construcao-civil-quais-sao-as-melhores-aplicacoes/>. Acesso em: 12 mar. 2019. 